\title{
Discussion on Structure Design and Optimization of Building Curtain Wall
}

\author{
Zhenwen Gong, Bin Zeng, Weichi Han, Suduo Xue \\ Jangho Group Co., Ltd., Beijing, China \\ Email: gongzw@jangho.com
}

How to cite this paper: Gong, Z.W., Zeng, B., Han, W.C. and Xue, S.D. (2017) Discussion on Structure Design and Optimization of Building Curtain Wall. Open Journal of Civil Engineering, 7, 303-310. https://doi.org/10.4236/ojce.2017.72020

Received: May 25, 2017

Accepted: June 23, 2017

Published: June 26, 2017

Copyright $\odot 2017$ by authors and Scientific Research Publishing Inc. This work is licensed under the Creative Commons Attribution International License (CC BY 4.0).

http://creativecommons.org/licenses/by/4.0/ (c) (i) Open Access

\begin{abstract}
To discuss the structure design and optimization of building curtain wall, the dynamic characteristics of point supported glass curtain wall system are analyzed by the finite element method. The various technologies are made use of, and according to the characteristics of the structure system, the finite element analysis model with steel structure glass plate beam element and shell element as the basic elements is established. Then, the dynamic characteristics are analyzed, and the modal parameters such as inherent frequency and vibration type are identified. The research results show that the node displacement response power spectrum under the load of wind is obtained, which provides the basis for rationally optimizing the structure. Based on the above findings, it is concluded that the optimization design based on finite element model has a wide significance, which is a useful attempt to reduce the blindness of design and has great engineering significance and application value.
\end{abstract}

\section{Keywords}

Structure Design, Curtain Wall, Finite Element Analysis

\section{Introduction}

The characteristics of point supported glass curtain wall in glass curtain wall is that it has high permeability, and the supporting structure is concise and lively, which shows the melody beauty of point connecting structure and modern sense of glass support structure system. With the progress of glass technology and a large number of public building construction, point supported glass curtain wall is more and more widely applied at home and abroad [1]. Because the supporting structure of point supported glass curtain wall is expanding constantly, the lattice steel structure can well meet the above requirements, and it has been widely used in the supporting structure of point supported glass curtain wall. In order to give a different hue to a building under different external light condi- 
tions and show dynamic beauty of buildings, it requires to re-design and optimize the building curtain wall structure. What's more, in the development of building curtain wall, some problems appeared, which seriously affect the prospect of building curtain wall. For solving these problems and promoting the further development of it, it is necessary to make an optimization. With the use of CAE technology, according to the characteristics of the system of point supported glass curtain wall structure, finite element analysis model with steel structure glass plate beam element and shell element as the basic elements is established, the connection between the structure and boundary conditions is rationally simulated, and the modal analysis is carried out, to identify the modal parameters. According to the design schemes, the dynamic characteristics are completely analyzed and compared. In addition, calculation of dynamic sensitivity based on finite element analysis is carried out. And the point supported glass curtain wall structure system is divided into several components according to the actual situation, with each component as a group. Through the numerical analysis software, corresponding program is compiled, and dynamic sensitivity is calculated by using difference method. On the basis of dynamic sensitivity analysis, the dynamic modification research on point supported glass curtain wall system is carried out, and the effective design variables are selected to optimize the dynamic design, and the corresponding conclusions are obtained.

\section{Methods}

With the rapid development of modern engineering technology, higher requirements have been put forward for the modeling and applicability of buildings. The supporting structures in buildings are becoming more and more light, and the requirements for structural dynamic characteristics are increasing. As the building envelope structure, the structure of the curtain wall is becoming lighter and lighter, so the vibration of the structure is more prominent. Building curtain wall industry is an edge industry. Compared with the main structure of building, the analysis of its dynamic characteristics is still a blank [2]. Therefore, a thorough understanding of the dynamic characteristics of point supported glass curtain wall supporting structures should be essential. In this paper, the finite element analysis model is established according to the characteristics of the point supported glass curtain wall structure system, and the modal analysis is carried out. It is a useful attempt for the application of the technology in the design of modern building curtain wall.

\subsection{Finite Element Model of Large Point Supported Glass Curtain Wall}

The whole structure of the point supported glass curtain wall is composed of a glass faceplate, a supporting structure, a supporting structure connecting the glass and the supporting device. Glass curtain wall facade dimension is 62.7 meters in width, and 20.95 meters in height, and the entire building has been included. According to the characteristics of the project, in order to ensure trans- 
parent glass properties and buildings inside and outside space circulation and integration, two schemes are put forward. Scheme 1 is that the top of tapered I-beam and steel pipe span out is connected with tube type steel frame structure; and scheme 2 is that the top with variable cross section I-beam spanning out is connected with Fishbelly steel structure [3]. Both of the two schemes do not depend on the main structure for load transfer, which is the plane truss alone force system. In order to ensure the supporting structure strength, stiffness and stability, we add silicon strip (beam foundation) at the bottom of root. Taking into account the size of glass original piece and process of glass deep processing, two schemes use the same transparent white laminated glass, with cell size of $1.6 *$ $1.9 \mathrm{~m}$, and both use a series of 250 floating connection system.

The glass of point supported glass curtain wall is connected to point supported glass curtain wall supporting structure through a series of floating connection systems, and the thickness of the glass relative to the area is less than $1 \%$. As a result, the glass unit is established by using shell 63 housing unit, which is connected to the supporting structure at the four corners of the glass. In the support structure, tapered I-beam root is fixed connected with the building, and the end, with the ear plate and pin, is connected with tube type steel frame or lenticular steel truss hinge. Therefore, the beam 44 element is used to establish tapered I-beam unit, root fixed constraint, and the end of the tubular steel frame or Fishbelly steel truss is coupling for hinge. Tubular steel frame or Fishbelly steel truss uses pin shaft to connect with the ear plate, and the ear plate is fixed on a concrete foundation. In consequence, the beam element is adopted to build the tubular steel frame or lenticular steel truss element, and the upper part of tapered I-beam girder is hinged with the lower coupling, and the coupling is hinged with the base.

\subsection{Establishment of Finite Element Analysis Model}

Considering the basic principle of finite element method, the finer the mesh division is, the closer it is to the actual structure, but the time of dynamic analysis and calculation will increase exponentially. The two factors influence each other and restrict each other, so we must consider it as a whole. Under the premise that the calculation accuracy is satisfied, the machine time is shortened as much as possible, and the operation efficiency is improved. As mentioned above, according to the characteristics of the point supported glass curtain wall structure system, finite element analysis model with steel structure glass plate beam element and shell element as the basic element is established, and the reasonable connection and boundary conditions between structures are rationally simulated [4]. In addition, the division grid is considered and determined, and a finite element method analysis model for two schemes is established, shown in Figure 1 and Figure 2, respectively.

Scheme 1 (tubular steel frame) structure description: Cross section of variable section I-beam is $300 * 300$ to $300 * 700$; steel plate thickness is $14 \mathrm{~mm}$; pipe type

steel frame riser is $\phi 273 * 10 \mathrm{~mm}$; horizontal pipe is $\phi 165 * 4.5 \mathrm{~mm}$; variable 


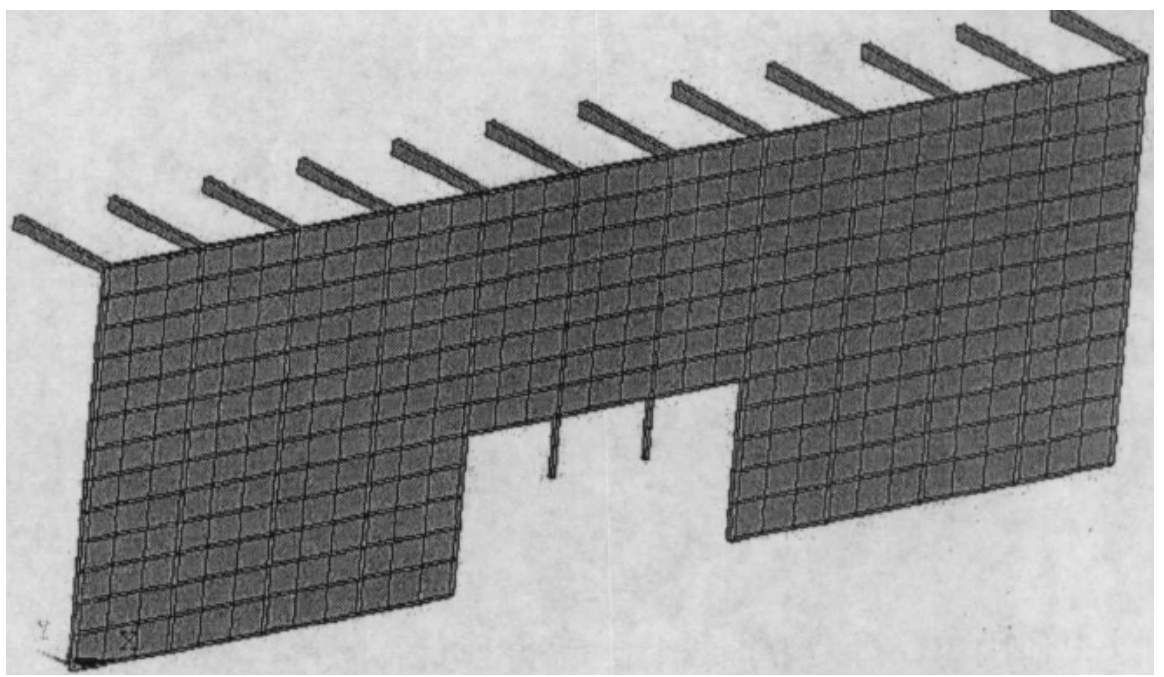

Figure 1. Finite element model of tubular steel frame.

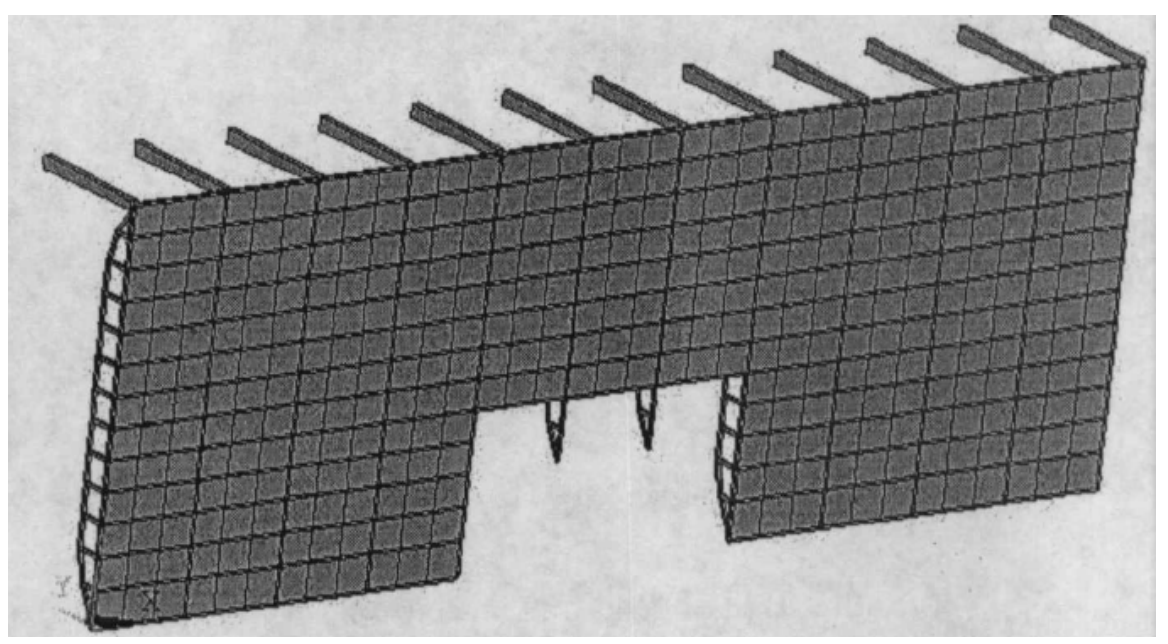

Figure 2. Finite element model of Fishbelly steel truss.

span I-beam span is $7 \mathrm{~m}$; vertical height and spacing of pipe type steel frame are $20.95 \mathrm{~m}$ and $5.9 \mathrm{~m}$, respectively. $10+1.52 \mathrm{PVB}+8 \mathrm{~mm}$ transparent laminated glass is applied, the grid division size is $1.6 * 1.9 \mathrm{~m}$, and a series of 250 floating barge systems are used.

Scheme 2 (Fishbelly steel truss) structure description: Cross section of variable section I-beam is $300 * 300$ to $300 * 700$; steel plate thickness is $14 \mathrm{~mm}$; Fishbelly steel truss front riser is $\phi 219 * 8 \mathrm{~mm}$, latter riser is $\phi 140 * 4.5 \mathrm{~mm}$, and belly bar is $\phi 114 * 3.5 \mathrm{~mm}$; horizontal pipe is $\phi 165 * 4.5 \mathrm{~mm}$; variable span I-beam span is $7 \mathrm{~m}$, Fishbelly steel truss height is $20.95 \mathrm{~m}$, and the spacing is $5.9 \mathrm{~m} .10+$ $1.52 \mathrm{PVB}+8 \mathrm{~mm}$ transparent laminated glass is applied, the grid division size is $1.6 * 1.9 \mathrm{~m}$, and a series of 250 floating barge systems are used.

\subsection{Modal Analysis}

After the finite element analysis, the point supported glass curtain wall system is discretized into a system with $\mathrm{n}$ degrees of freedom. Dynamic equilibrium equa- 
tion is:

$$
[M] \cdot\{\ddot{x}\}+[C] \cdot\{\dot{x}\}+[K] \cdot\{x\}=\{F(t)\}
$$

In the above formula, $\{F(t)\}$ refers to the exciting force array; $\{x\}$ indicates the displacement array; $[M],[C]$, and $[K]$ are quality, stiffness, and resistance array, respectively.

Without external forces, that is $\{F(t)\}=\{0\}$, we can get the free vibration equation; in the actual engineering issues, the impact of resistance on the structure fixed frequency and vibration type is not great so that it can be ignored. Then we get the free vibration equation without resistance:

$$
[M] \cdot\{\ddot{x}\}+[K] \cdot\{x\}=\{0\}
$$

In the free vibration, we set the nodes have simple harmonic vibration, and its displacement can be expressed as:

$$
\{x\}=\{X\} \cdot \sin (\omega \cdot t+\varphi)
$$

In (3), $\{X\}$ indicates the vibration type vector; $\omega$ suggests the fixed frequency that the vibration type corresponds to; and $\{\varphi\}$ refers to the phase angle. Substituting (3) into the free vibration equation without resistance, we can get:

$$
\left([K]-\omega^{2} \cdot[M]\right) \cdot\{X\}=\{0\}
$$

The necessary and sufficient condition with not zero solution of (4) is:

$$
\left|[K]-\omega^{2} \cdot[M]\right|=0
$$

Now that in the general finite element analysis, the degrees of freedom of the system are of variety, and in the study of the dynamic characteristics, we often only need to know a few lower order eigenvalues and corresponding eigenvectors, in finite element analysis, some effective solutions that adapt to the above features are developed [5]. The widely used methods include the subspace iteration method, Block Lanczos method, and the reduction of freedom degree method.

Block Lanczos algorithm used in the study means to use a group of vectors to realize Lanczos recursive computation. This method, similar to the subspace method, is accurate, and the speed is faster and the solution efficiency is higher. No matter what kind of solution machine is used for the solution, Block Lanczos method can automatically apply sparse matrix equation to solve the problem, which is especially suitable for large eigenvalue problems.

\section{Result Analysis}

Because only the lower natural frequencies and modes have great influence on the structural dynamics, the natural frequencies and modes of the point supported glass curtain wall system are calculated mainly in this paper.

The modal analysis of the structure is helpful to the further study of the structural vibration and provides a reliable basis for the structural design. For the general structure, the vibration of the structure can be discretely expressed as 
a linear combination of the order natural frequency. The dynamic effect of low order natural modes is stronger than that of the high order modes. As a result, the low order modes determine the dynamic characteristics of the structure.

Taking the study of modal structure of point supported glass curtain wall as the major work, Table 1 and Table 2 show a list of the natural frequency of pipe steel in scheme 1 and that of Fishbelly steel truss in scheme 2. The modal description refers to the main vibration forms of the order mode. From the table, it can be seen that, the basic modes of two schemes are both forward and backward vibration perpendicular to the direction of the glass [6]. In that the wall area is large, the left and right, and the middle parts, in their respective range and within the entire range, oppositely and reversely vibrate. The dynamic stiffness of the structure is small, and it will have an adverse impact on the glass and the barge system under the excitation of the fluctuating wind. It is not beneficial to the fatigue performance of the overall glass curtain wall system, and its overall dynamic performance should be further improved.

Compare scheme 1 and scheme 2, the steel structure weight of scheme 1 and scheme 2 is $34,806 \mathrm{~kg}$ and $38,399 \mathrm{~kg}$, respectively. For the steel structure weight, scheme 2 is 1.1 times of scheme 1 . The steel materials consumed has no great difference, while the dynamic characteristics of the two schemes are significantly different. The natural frequency in the first order of scheme 1 is only 0.75410 (HZ), no more than $35 \%$ of the natural frequency 2.2084 in the first order of

Table 1. Tube type steel frame.

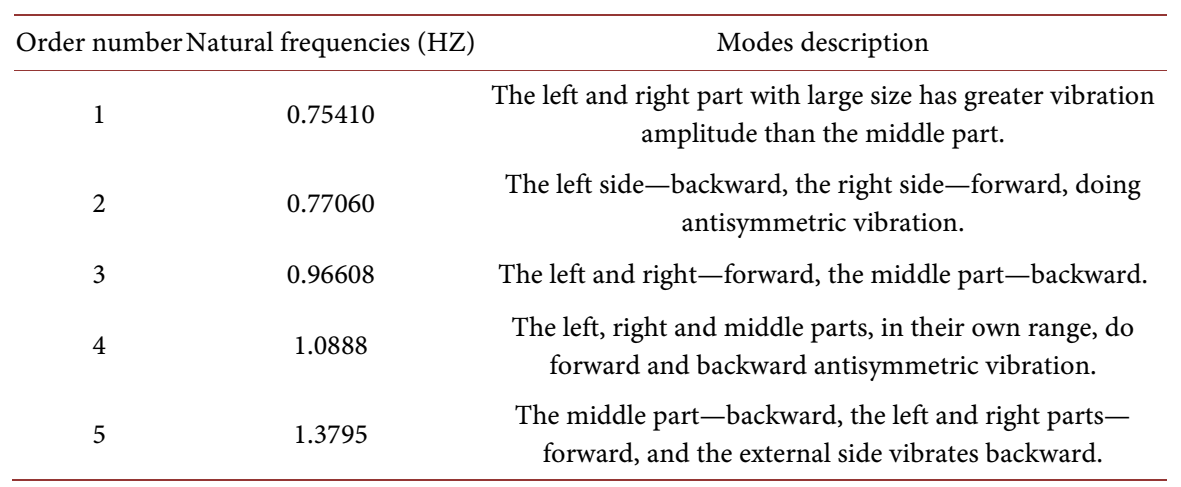

Table 2. Fishbelly steel truss.

\begin{tabular}{|c|c|c|}
\hline $\begin{array}{l}\text { Order } \\
\text { number }\end{array}$ & $\begin{array}{l}\text { Natural } \\
\text { frequencies }(\mathrm{HZ})\end{array}$ & Modes description \\
\hline 1 & 2.2084 & The left side-backward, the right side-forward. \\
\hline 2 & 2.2084 & $\begin{array}{l}\text { The left and right-forward, the middle part-backward, accompanied } \\
\text { with torsional vibration of Fishbelly steel truss. }\end{array}$ \\
\hline 3 & 2.4213 & $\begin{array}{l}\text { The left, right and middle parts, in their own range, do forward and } \\
\text { backward antisymmetric vibration. }\end{array}$ \\
\hline 4 & 2.4218 & $\begin{array}{l}\text { Middle part-backward, the left and right parts-forward, and the } \\
\text { external side vibrates forward. }\end{array}$ \\
\hline 5 & 2.8850 & $\begin{array}{l}\text { Middle part of right side-backward and the two sides-forward; } \\
\text { middle part of left side-forward and the two sides-backward. }\end{array}$ \\
\hline
\end{tabular}




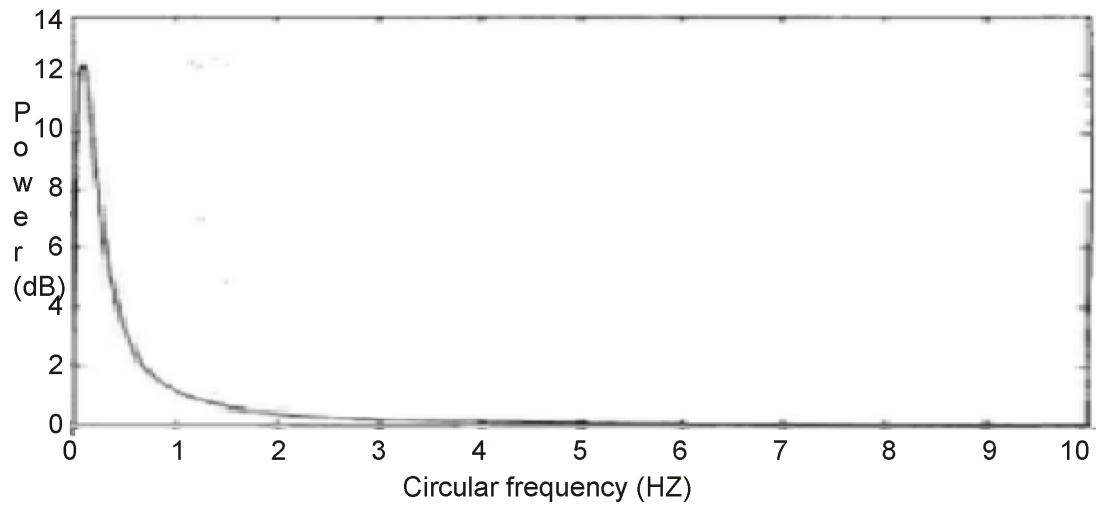

Figure 3. Davenport spectrum diagram.

scheme 2, and its dynamic stiffness is worse.

The fluctuating wind is a stochastic process, and the most widely used one is Davenport spectrum. And the wind spectrum is expressed as:

$$
S_{f f}(\omega)=\frac{4 \pi x_{0}^{2}}{3 \omega\left(1+x_{0}^{2}\right)^{\frac{4}{3}}}, \quad x_{0}=\frac{600 \omega}{\pi \bar{V}_{10}}
$$

$\bar{V}_{10}$ refers to the wind speed with the distance of 10 meters to the ground, which is generally selected according to the local statistics materials and design requirements, which is chosen as $\bar{V}_{10}=26.8 \mathrm{~m} / \mathrm{s}$.

With the use of the numerical analysis software, the spectrum diagram calculated in accordance with formula programming is shown in Figure 3.

According to Davenport spectrum, the fluctuating wind has the largest peak in the low frequency range of $0-1$ (Circular frequency $\omega, \mathrm{HZ}$ ), while the natural frequency in the first order of scheme 1 is only $0.75410 \mathrm{HZ}$ [7]. As a result, under the excitation of fluctuating wind, scheme 1 will generate great vibration. Through the comparison of dynamic characteristics, scheme 1 is eliminated, and scheme 2 is selected.

\section{Conclusion}

This paper uses CAE technology to analyze the dynamic characteristics of finite element analysis of point supported glass curtain wall structure system, so as to have a comprehensive understanding of dynamic characteristics of point supported glass curtain wall structure. In addition, based on the dynamic characteristics research results, the pseudo excitation method is used for random vibration analysis. The results show that the CAE technology is a feasible and effective analysis method in modern architectural structure design, so it is necessary to study the technology of point supported glass curtain wall system. The finite element method can accurately and effectively determine the dynamic characteristics of complex structures, and has important engineering application value.

\section{Acknowledgements}

I would like to express my gratitude to all those who helped me during the writing 
of this thesis. I gratefully acknowledge the help of my supervisor who has offered me valuable suggestions in the academic studies. In the preparation of the thesis, she has spent much time reading through each draft and provided me with inspiring advice. Without her patient instruction, insightful criticism and expert guidance, the completion of this thesis would not have been possible. I also owe a special debt of gratitude to all the professors in Foreign Languages Institute, from whose devoted teaching and enlightening lectures I have benefited a lot and academically prepared for the thesis.

\section{References}

[1] Feng, Z. and Feng, J. (2016) Design and Implementation of Wind Load Resistance Performance Data Acquisition System of Building Curtain Wall. International Journal of Hybrid Information Technology, 9, 83-100. https://doi.org/10.14257/ijhit.2016.9.2.08

[2] Oh, J.M., Song, J.H., Lim, J.H. and Song, S.Y. (2016) Analysis of Building Energy Savings Potential for Metal Panel Curtain Wall Building by Reducing Thermal Bridges at Joints between Panels. Energy Procedia, 96, 696-709. https://doi.org/10.1016/j.egypro.2016.09.129

[3] Kong, X., Liu, S., Yang, H., Zhong, Y. and Qi, C. (2016) An Experimental Study of All-Season Operation Strategy for a Respiration-Type Double-Layer Glass Curtain Wall System in Cold Zone of China. Building and Environment, 97, 166-176. https://doi.org/10.1016/j.buildenv.2015.11.030

[4] Gil, M.S., Kim, S.H., Lee, Y.S., Lee, S.H. and Han, C.S. (2016) The Study on the Integrated Control System for Curtain Wall Building Cleaning Robot. Proceedings of the International Symposium on Automation and Robotics in Construction, Vilnius Gediminas Technical University, Vol. 33, 1.

[5] Lee, A.D., Shepherd, P., Evernden, M.C. and Metcalfe, D. (2017) Optimizing the Cross-Sectional Shapes of Extruded Aluminium Structural Members for Unitized Curtain Wall Facades. Structures, 10, 147-156.

[6] Appelfeld, D. (2017) Thermal Optimization of Curtain Wall Façade by Application of Aerogel Technology. Journal of Facade Design and Engineering, 5, 118-127. https://doi.org/10.1002/cepa.37

[7] Lam, T.C., Ge, H. and Fazio, P. (2016) Energy Positive Curtain Wall Configurations for a Cold Climate Using the Analysis of Variance (ANOVA) Approach. Building Simulation, 9, 297-310. https://doi.org/10.1007/s12273-016-0275-6 
Submit or recommend next manuscript to SCIRP and we will provide best service for you:

Accepting pre-submission inquiries through Email, Facebook, LinkedIn, Twitter, etc. A wide selection of journals (inclusive of 9 subjects, more than 200 journals)

Providing 24-hour high-quality service

User-friendly online submission system

Fair and swift peer-review system

Efficient typesetting and proofreading procedure

Display of the result of downloads and visits, as well as the number of cited articles Maximum dissemination of your research work

Submit your manuscript at: http://papersubmission.scirp.org/

Or contact ojce@scirp.org 